\title{
Treatment of rectal cancer in the older population
}

\author{
Jakub Kenig \\ Department of General, Gastrointestinal, Oncologic Surgery and Transplantology, I Chair of General Surgery, \\ Jagiellonian University Medical College, Krakow, Poland
}

The majority of rectal cancer patients are elderly. Biological age, not chronological age alone, is the main risk factor of postoperative morbidity in this group. Therefore, based on the Comprehensive Geriatric Assessment, we can differentiate three groups of patients: fit, pre-frail and frail. In the fit group, a standard multimodal oncologic treatment can be offered. In the pre-frail group, prerehabilitation should be recommended to improved resilience to surgical stress. In frail patients, a tailored approach should be discussed in a geriatric multidisciplinary team meeting. At present, a whole range of multimodal tailored approaches can be offered to rectal cancer patients. In this group, of much more importance is postoperative functional recovery, including both organ-specific outcomes and the ability to regain independence than currently used outcome indicators. Therefore, as important as cancer staging and tumour biology, it is crucial to understand the health status of an older patient with rectal cancer.

Key words: rectal cancer, older patients, frailty, elderly

The majority of rectal cancer $(\mathrm{RC})$ patients are elderly, diagnosed at a median age of 70 years. However, the risk of developing rectal cancer still increases with age, so octoand nonagenarians with rectal tumours are, currently, also not a rarity [1].

The major problem in tailored treatment of $\mathrm{RC}$ in older patients is still the lack of good research data. Older patients are still not sufficiently included in studies. In 2019, Abbasi et al. demonstrated that the proportion of older patients in clinical trials is $<25 \%$ (age $65-74$ years) and $<10 \%$ (age 75 and more), respectively [2]. In turn, Schiphorst et al., analysing the participation of older patients in laparoscopic surgery for colorectal cancer, showed that the median age was less than 65 years in $86 \%$ of the studies, and $44 \%$ of the studies excluding the elderly [3]. This shows that the guidelines for the treatment of the elderly are still based on the extrapolation of evidence obtained from studies including patients from younger age groups or older patients who were completely healthy. Therefore, older patients with $\mathrm{RC}$ are often under-treated due to their chronological age or poorly evaluated co-morbidities, or over-treated due to failures in recognising the frailty status of the patient [4].

Due to improvements in anaesthesia, surgical techniques and perioperative care in developed countries, significant decreases in perioperative morbidity and mortality are observable. However, the 5-year absolute survival and disease-free survival of older patients are still significantly poorer in comparison to younger patients. Therefore, increasing the awareness of physicians treating $\mathrm{RC}$ is one of the main goals of this mini-review based on recently published studies and the expert recommendations of the European Society of Surgical Oncology, the European Society of Coloproctology, the International Society of Geriatric Oncology, and the American College of Surgeons Commission on Cancer [5-9].

\section{How to cite:}

Kenig J. Treatment of rectal cancer in the older population. NOWOTWORY J Oncol 2021; 71: 165-168.

This article is available in open access under Creative Common Attribution-Non-Commercial-No Derivatives 4.0 International (CC BY-NC-ND 4.0) license, allowing to download articles and share them with others as long as they credit the authors and the publisher, but without permission to change them in any way or use them commercially. 


\section{Preoperative assessment and treatment decisions}

As was mentioned in our previous publications, the population of older patients is very heterogeneous in terms of co-morbidity, physical reserve, cognitive function and social support $[10,11]$. Current routine preoperative assessment also cannot adequately identify patients at risk. Therefore, the comprehensive geriatric assessment (CGA) was introduced to help determine the primary status of the older patient, to diagnose frailty syndrome (surrogate of biological age) and to identify how to optimise the patient's condition before the start of the treatment. A standardised preoperative diagnostic approach, individualised surgical technique selection and tailored postoperative care are essential for the successful treatment of older patients $[6,12]$. In general, based on the CGA, we can differentiate 3 groups of older patients:

1. Fit: patients without any deficits in the CGA domains and less than 80 years old. In this group, the standard oncologic treatment can be offered and the postoperative outcomes are comparable with younger patients.

2. Pre-frail: patients with 1 or 2 deficits in the CGA domains or more than 80 years old. In these patients, pre-rehabilitation should be recommended to improve resilience to surgical stress by, at least, augmenting functional capacity and nutritional status before surgery.

3. Frail: patients with 3 or more impaired domains in the CGA or 80 years old with 2 deficits in the CGA. A tailored approach should be discussed in a geriatric multidisciplinary team meeting [6].

\section{Important treatment outcomes for older patients}

The outcomes of cancer treatment in older patients should be evaluated differently and should be discussed with the patient before surgery. The 5-year overall survival, the disease specific survival, or the progression-free survival are well established indicators to define cancer control. However, these indicators have limited value for patients aged $80+$ years, and particularly, for frail patients independent of their chronological age. In this group, of much more importance is the functional recovery indicators, including both organ-specific postoperative outcomes and the ability to regain independence. In the case of rectal cancer, organ-specific' outcomes should include evaluation of urinary, sexual, bowel function, faecal incontinence and, in the case of a diverting loop ileostomy, its closure after primary operation. Similarly, we need more studies on the time and level of posttreatment independence restoration. Good quality data on these topics in frail patients are still not available [5]

\section{Treatment of rectal cancer in older patients}

Table I presents the therapeutic options for rectal cancer patients depending on the risk group based on guidelines, supplemented by information on possible treatment options for frail patients [7]. However, it must be stressed that diagnosing frailty in a patient is not a contraindication for surgery. It is a sign that standard oncologic treatment can lead to unacceptable results; major morbidity, permanent disability, institutionalisation and death. Moreover, frailty is not a qualitative indicator (present or not). It can be quantified and there are significant differences between mild and severely frail patients.

Table I. Therapeutic options for rectal cancer patients depending on the risk group [7], including options for frail older patients

\begin{tabular}{|c|c|c|c|}
\hline Risk group & Stage factors & Fit patients & Frail patients \\
\hline very early & cT1 sm1-2, N0 & $\begin{array}{l}\text { local excision } \\
\text { TME in case of sm3, IMVI(+), } \\
\text { G3-4 }\end{array}$ & - local excision \\
\hline early & $\begin{array}{l}\text { CT1-2 } \\
\text { cT3aNO, middle or high rectum, } \\
\text { MRF(-), EMVI(-) } \\
\text { CT3aN1 high rectum, MRF(-), EMVI(-) }\end{array}$ & $\begin{array}{l}\text { TME } \\
\text { in case of CRM(+), N2: adjuvant } \\
\text { treatment }\end{array}$ & $\begin{array}{l}\text { - local excision }+ \text {--adjuvant treatment } \\
\text { - prerehabilitation followed by TME } \\
\text { - neoadjuvant CRTh with watch-and-wait strategy in } \\
\text { case of complete clinical response } \\
\text { - palliative care in sever frailty }\end{array}$ \\
\hline intermediate & $\begin{array}{l}\text { cT3a/b in low rectum, levators } \\
\text { clear, MRF(-) } \\
\text { cT3a/b in mid- or high rectum, } \\
\text { cN1-2, no EMVI }\end{array}$ & $\begin{array}{l}\text { neoadjuvant RTh }(5 \times 5 \text { Gy) or } \\
\text { CRTH followed by TME }\end{array}$ & $\begin{array}{l}\text { - neoadjuvant rth } 5 \times 5 \text { with longer time interval (in the } \\
\text { mean time prerehabilitation) and TME } \\
\text { - neoadjuvant CRTh with watch-and-wait strategy in } \\
\text { case of complete clinical response (in the mean time } \\
\text { prerehabilitation) } \\
\text { - prerehabilitation followed by TME } \\
\text { - palliative care in sever frailty }\end{array}$ \\
\hline advanced & $\begin{array}{l}\text { CT3 with MRF }(+) \\
\text { any cT4a-b } \\
\text { pelvic lateral } \mathrm{N}+\end{array}$ & $\begin{array}{l}\text { neoadjuvant CRTh followed by } \\
\text { TME or more extended surgery }\end{array}$ & $\begin{array}{l}\text { - neoadjuvant RTh } 5 \times 5 \text { with longer time interval (in } \\
\text { the mean time prerehabilitation) and TME or more } \\
\text { extended surgery } \\
\text { - neoadjuvant CRTh (in the mean time prerehabilitation) } \\
\text { followed by TME or more extended surgery } \\
\text { - palliative care in sever frailty }\end{array}$ \\
\hline
\end{tabular}

sm - submucosa; V1 - cancer cells in the vessels; G - grading; CRM - circumferential resection margin; MRF - mesorectal fascia; EMVI - presence of extramural venous invasion; IMVI - intramural vascular invasion; TME - total mesorectal excision; RTh - radiotherapy; CRTh - chemoradiotherapy 
Local excision (irrespective of platform used), in experience hands, can achieve good oncologic results, sparing the rectum, while lowering morbidity (7-14\%) with very good functional results (1\% urinary dysfunction, $<1$ faecal incontinence) [5]. According to the guidelines, the rectal cancer most suitable for local excision is T1 cancer with submucosal invasion $<1000 \mu m$, without lymphovascular invasion, well-differentiated and with budding grade 1. There are several studies on its use in T1 rectal cancer with poor pathology and $\mathrm{T} 2$ tumours with/without neodjuvant/adjuvant treatment or its combination. This strategy cannot be regarded as a standard of treatment due to the high recurrence rate. However, it can be considered in frail patients in combination with or without neo-/adjuvant treatment. Studies clearly show that neoadjuvant treatment is connected to a higher complication rate in comparison to adjuvant treatment. $[13,14]$.

There is still the belief that older patients cannot undergo a total mesorectal excision (TME) due to the high rate of perioperative complications. In the past, this type of operation was not advised in patients aged 75 years or more [15]. As was mentioned before, currently the chronological age alone does not determine the choice of treatment.

Similarly, advanced age had initially been viewed as a relative contraindication to minimal invasive surgery due to the physiologic influence of pneumoperitoneum on the older patient. Based on well-known trials, COLOR II, CLASICC, COST, we know that minimal invasive rectal cancer surgery is safe and has comparable oncological results as open surgery [16-18]. None of these studies excluded elderly patients based on their chronological age. However, older patients were underrepresented compared to younger patients. Li Y et al. analysed 11 studies on colorectal resection in octogenarians and proved that laparoscopy is safe and carries a lower risk of infectious complications (pulmonary and surgical site), a shorter length of hospital stay and a reduced incidence of postoperative ileus while maintaining the same cardiovascular risk as compared to open surgery [19]. These benefits are pointed out by Senagore et al., showing decreased direct costs associated with laparoscopic surgery in older patients [20]. A study of 33,000 patients in the Netherland's Cancer Registry showed that the reduction in 1-year mortality associated with laparoscopic resection was greatest in the population of patients greater than 75 years of age [21]. However, laparoscopic TME is still performed in only $10-50 \%$ of all rectal cancers with a high conversion rate (up to $30 \%$ ).

A few published studies on robotic colorectal surgery in the geriatric population reported similar oncologic outcomes to the laparoscopic approach, although with increased costs and longer operative time [22-24].

Studies on Transanal TME (taTME) in older patients are not currently available. Based on data from the International taTME registry, managed by the Pelican Cancer Foundation, in $92 \%$ of the older study population, a sphincter-preserving procedure was carried out. The conversion rate was low (5\%). The overall 30-day mortality and morbidity were 1\% and 38\%, respectively. There was no difference in the number of surgical complications between the older and younger rectal cancer patients. Therefore, age alone is not a contraindication to minimal invasive surgery. Laparoscopy seems to be the preferred option to perform TME surgery in older patients. The benefits of laparoscopy are consistent with the expectations of geriatric surgery [5].

\section{Neoadjuvant chemoradiation}

Neoadjuvant radiotherapy is the standard treatment for locally-advanced mid-distal rectal cancer to increase local control. If the radial margin is not threatened, the preoperative radiotherapy $5 \times 5$ Gy with immediate operation is most commonly used. In frail patients, a longer time (4-8 weeks) between the end of the radiation and the surgery is recommended to reduce the complication rate. Over this time, prerehabiliation can be carried out to improve resilience to surgical stress by, at least, augmenting functional capacity and nutritional status before surgery. In the case of a larger tumour, with a threatened radial margin, a 45-50 Gy dose of radiotherapy is given over 5 weeks. Concurrent chemotherapy is also administered. However, in older patients, the toxicity of this treatment may compromise the chance of TME surgery, which is the main treatment for local control and curative intent. In turn, in up to 25-30\%, a complete clinical response can be achieved [25]. This so-called watch and wait strategy, allows to preserve rectum avoids preoperative morbidity, a permanent stoma or long-term functional problems associated with TME surgery. However, up to 30\% have a regrowth. Detected early, it can be successfully treated with delayed TME surgery.

Smith et al. compared cohorts: 60-year-old men with mild co-morbidities, 80-year-olds with minor co-morbidities, and 80 -year-olds with significant co-morbidities. Patients with a complete clinical response after chemoradiotherapy were followed according to the watch and wait protocol or had TME. There was no difference in absolute survival in 60-year-old patients from the watch and wait and TME group. However, in both the 80 -year-old groups, there was a $10.1 \%$ survival advantage at the one year mark in those who underwent a watch and wait protocol $[26,27]$.

\section{Adjuvant chemotherapy}

Adjuvant chemotherapy is typically given following surgical resection with or without neoadjuvant chemoradiotherapy. Several studies have been carried out to evaluate the benefits of adjuvant chemotherapy for rectal cancer. Breugom et al. and Bujko et al. performed two meta-analyses on this topic. The first showed no difference in overall survival, disease free survival, or the rate of distant recurrence. In a subgroup analysis, the authors observed an increase in disease free survival and a decreased rate of distant recurrences in tumours between 
10 and $15 \mathrm{~cm}$ from the anal verge [28]. The second showed no benefit for postoperative chemotherapy in improving overall survival or disease free survival [29]. Therefore, the SIOG consensus on postoperative chemotherapy in colorectal cancer in older patients advocates a risk-balanced approach [30].

\section{Conflict of interest: none declared}

\author{
Jakub Kenig \\ Jagiellonian University Medical College \\ I Chair of General Surgery \\ Department of General, Oncologic, Gastrointestinal Surgery and \\ Transplantology \\ ul. Jakubowskiego 2 \\ 30-688 Kraków, Poland \\ e-mail:jkenig@cm-uj.krakow.pl
}

\section{Received: 17 Apr 2021}

Accepted: 21 Apr 2021

\section{References}

1. Smith BD, Smith GL, Hurria A, et al. Future of cancer incidence in the United States: burdens upon an aging, changing nation. J Clin Oncol. 2009; 27(17): 2758-2765, doi: 10.1200/JCO.2008.20.8983, indexed in Pubmed: 19403886

2. Abbasi J. Older Patients (Still) Left Out of Cancer Clinical Trials. JAMA. 2019; 322(18): 1751-1753, doi: 10.1001/jama.2019.17016, indexed in Pubmed: 31647507.

3. Schiphorst AHW, Pronk A, Borel Rinkes IHM, et al. Representation of the elderly in trials of laparoscopic surgery for colorectal cancer. Colorectal Dis. 2014; 16(12): 976-983, doi: 10.1111/codi.12806, indexed in Pubmed: 25331635.

4. Lawler M, Selby P, Aapro MS, et al. Ageism in cancer care. BMJ. 2014; 348(feb28 1): g1614-g1614, doi: 10.1136/bmj.g1614

5. Montroni I, Ugolini G, Saur NM, et al. Personalized management of elderly patients with rectal cancer: Expert recommendations of the European Society of Surgical Oncology, European Society of Coloproctology, International Society of Geriatric Oncology, and American College of Surgeons Commission on Cancer. Eur J Surg Oncol. 2018; 44(11): 1685-1702, doi: 10.1016/j.ejso.2018.08.003, indexed in Pubmed: 30150158

6. Tomasz G, Kenig J. Problemy okołooperacyjne u osób w wieku podeszłym. PZWL Wydawnictwo Lekarskie 2018.

7. Glynne-Jones R, Wyrwicz L, Tiret E, et al. ESMO Guidelines Committee Rectal cancer: ESMO Clinical Practice Guidelines for diagnosis, treatment and follow-up. Ann Oncol. 2017; 28(suppl 4): iv22-iv40, doi: 10.1093/annonc/mdx224, indexed in Pubmed: 28881920.

8. Saur NM, Montroni I, Shahrokni A, et al. Care of the Geriatric Colorectal Surgical Patient and Framework for Creating a Geriatric Program: A Compendium From the 2019 American Society of Colon and Rectal Surgeons Annual Meeting. Dis Colon Rectum. 2020; 63(11): 1489-1495, doi: 10.1097/DCR.0000000000001793, indexed in Pubmed: 32947418.

9. NICE guideline Published: 29 January 2020. www.nice.org.uk/guidance/ ng151.

10. Kenig J. Oncogeriatrics (part 4.) Pre-operative assessment of elderly patients with cancer. Nowotwory. Journal of Oncology. 2020; 70(1): 16-19, doi: 10.5603/njo.2020.0003.

11. Kenig J. Oncogeriatrics (part 1.). Frailty in older adults with cancer. Nowotwory. Journal of Oncology. 2019; 69(2): 55-57, doi: 10.5603/ njo.2019.0010.

12. Xue $D D$, Cheng $Y$, Wu $M$, et al. Comprehensive geriatric assessment prediction of postoperative complications in gastrointestinal cancer patients: a meta-analysis. Clin Interv Aging. 2018; 13: 723-736, doi: 10.2147/CIA.S155409, indexed in Pubmed: 29731614.

13. Perez RO, Habr-Gama A, São Julião GP, et al. Transanal endoscopic microsurgery for residual rectal cancer after neoadjuvant chemoradiation therapy is associated with significant immediate pain and hospital readmission rates. Dis Colon Rectum. 2011; 54(5): 545-551, doi: 10.1007/DCR.0b013e3182083b84, indexed in Pubmed: 21471754.
14. Borstlap WAA, Coeymans TJ, Tanis PJ, et al. Meta-analysis of oncological outcomes after local excision of pT1-2 rectal cancer requiring adjuvant (chemo)radiotherapy or completion surgery. Br J Surg. 2016; 103(9): 1105-1116, doi: 10.1002/bjs.10163, indexed in Pubmed: 27302385.

15. Rutten HJT, den Dulk M, Lemmens VE, et al. Controversies of total mesorectal excision for rectal cancer in elderly patients. Lancet Oncol. 2008; 9(5): 494-501, doi: 10.1016/S1470-2045(08)70129-3, indexed in Pubmed: 18452860.

16. Bonjer HJ, Deijen CL, Abis GA, et al. COLOR II Study Group. A randomized trial of laparoscopic versus open surgery for rectal cancer. N Engl J Med. 2015; 372(14): 1324-1332, doi: 10.1056/NEJMoa1414882, indexed in Pubmed: 25830422.

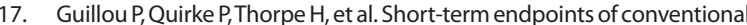
versus laparoscopic-assisted surgery in patients with colorectal cancer (MRC CLASICC trial): multicentre, randomised controlled trial. The Lancet. 2005; 365(9472): 1718-1726, doi: 10.1016/s0140-6736(05)66545-2.

18. Nelson H, Sargent DJ, Wieand HS, et al. Clinical Outcomes of Surgical Therapy Study Group. A comparison of laparoscopically assisted and open colectomy for colon cancer. N Engl J Med. 2004; 350(20): 2050 2059, doi: 10.1056/NEJMoa032651, indexed in Pubmed: 15141043.

19. LiY, Wang S, Gao S, et al. Laparoscopic colorectal resection versus open colorectal resection in octogenarians: a systematic review and meta-analysis of safety and efficacy. Tech Coloproctol. 2016; 20(3): 153-162, doi: 10.1007/s10151-015-1419-x, indexed in Pubmed: 26783029.

20. Senagore AJ, Madbouly KM, Fazio VW, et al. Advantages of laparoscopic colectomy in older patients. Arch Surg. 2003; 138(3): 252-256, doi: 10.1001/archsurg.138.3.252, indexed in Pubmed: 12611568.

21. Hamaker ME, Schiphorst AH, Verweij NM, et al. Improved survival for older patients undergoing surgery for colorectal cancer between 2008 and 2011. Int J Colorectal Dis. 2014; 29(10): 1231-1236, doi: 10.1007/ s00384-014-1959-y, indexed in Pubmed: 25024043.

22. Jayne D, Pigazzi A, Marshall $H$, et al. Effect of Robotic-Assisted vs Conventional Laparoscopic Surgery on Risk of Conversion to Open Laparotomy Among Patients Undergoing Resection for Rectal Cancer: The ROLARR Randomized Clinical Trial. JAMA. 2017;318(16): 1569-1580, doi: 10.1001/jama.2017.7219, indexed in Pubmed: 29067426

23. Ceccarelli G, Andolfi E, Biancafarina A, et al. Robot-assisted surgery in elderly and very elderly population: our experience in oncologic and general surgery with literature review. Aging Clin Exp Res. 2017; 29(Suppl 1): 55-63, doi: 10.1007/s40520-016-0676-5, indexed in Pubmed: 27905087.

24. de'Angelis N, Abdalla S, Bianchi G, et al. Robotic Versus Laparoscopic Colorectal Cancer Surgery in Elderly Patients: A Propensity Score Match Analysis. J Laparoendosc Adv Surg Tech A. 2018; 28(11): 1334-1345, doi: 10.1089/lap.2018.0115, indexed in Pubmed: 29851362.

25. Habr-Gama A, Sabbaga J, Gama-Rodrigues J, et al. Watch and wait approach following extended neoadjuvant chemoradiation for distal rectal cancer: are we getting closer to anal cancer management? Dis Colon Rectum. 2013; 56(10): 1109-1117, doi: 10.1097/DCR.0b013e3182a25c4e, indexed in Pubmed: 24022527.

26. Smith FM, Rao C, Oliva Perez R, et al. Avoiding radical surgery improves early survival in elderly patients with rectal cancer, demonstrating complete clinical response after neoadjuvant therapy: results of a decision-analytic model. Dis Colon Rectum. 2015; 58(2): 159-171, doi: 10.1097/DCR.0000000000000281, indexed in Pubmed: 25585073.

27. Beets GL, Figueiredo NL, Habr-Gama A, et al. A new paradigm for rectal cancer: Organ preservation: Introducing the International Watch \& Wait Database (IWWD). Eur J Surg Oncol. 2015;41(12): 1562-1564, doi: 10.1016/j.ejso.2015.09.008, indexed in Pubmed: 26493223.

28. Breugom A, Swets M, Bosset JF, et al. Adjuvant chemotherapy after preoperative (chemo)radiotherapy and surgery for patients with rectal cancer: a systematic review and meta-analysis of individual patient data. The Lancet Oncology. 2015; 16(2): 200-207, doi: 10.1016/s14702045(14)71199-4.

29. Bujko K, Glimelius B, Valentini V, et al. Postoperative chemotherapy in patients with rectal cancer receiving preoperative radio(chemo) therapy: A meta-analysis of randomized trials comparing surgery \pm a fluoropyrimidine and surgery + a fluoropyrimidine \pm oxaliplatin. Eur J Surg Oncol. 2015; 41(6): 713-723, doi: 10.1016/j.ejso.2015.03.233, indexed in Pubmed: 25911110.

30. Papamichael D, Audisio RA, Glimelius B, et al. Treatment of colorectal cancer in older patients: International Society of Geriatric Oncology (SIOG) consensus recommendations 2013. Ann Oncol. 2015; 26(3): 463-476, doi: 10.1093/annonc/mdu253, indexed in Pubmed: 25015334. 